\title{
O TEXTO ESCRITO COMO RECURSO DIDÁTICO NAS AULAS DE EDUCAÇÃO FÍSICA: PERSPECTIVAS E EXPERIÊNCIAS DOS PROFESSORES
}

\author{
WRITTEN TEXTS AS A TEACHING RESOURCE IN PHYSICAL EDUCATION \\ CLASSES: TEACHERS' PERSPECTIVES AND EXPERIENCES
}

EL TEXTO ESCRITO COMO RECURSO DIDÁCTICO EN LAS CLASES DE EDUCACIÓN FÍSICA: PERSPECTIVAS Y EXPERIENCIAS DE LOS MAESTROS

Pollyane de Barros Albuquerque Vieira*, Elisabete dos Santos Freire*, Graciele Massoli Rodrigues ${ }^{\star * *}$

Palavras chave: Educação Física e treinamento. Materiais de ensino. Livros de Texto.
Resumo: Com o objetivo de analisar o texto escrito como recurso didático aplicado no ensino da Educação Física e compreender as percepções e práticas construídas por professores que utilizam este recurso em suas aulas, realizamos entrevistas com 21 professores. Os participantes acreditam na relevância desta intervenção, selecionam textos diversificados e relacionados com temáticas atuais da Educação Física, construindo um processo pedagógico coerente com o que propõe a literatura sobre a temática analisada. Assim, percebemos que eles se preocupam com a contribuição da Educação Física para a construção do leitor, sem deixar de lado os conhecimentos específicos da área.

Abstract: The aim of this study was to analyze written text as a teaching resource used to teach Physical Education and understand perceptions and practices constructed by teachers using that resource in their classes. We interviewed 21 teachers who believe in the relevance of this intervention, select diverse texts related to current Physical Education topics, building a consistent pedagogical process with what literature suggests on the topic. Therefore, we see that they care about the contribution of Physical Education for readers' construction, without neglecting the specific knowledge of the area.

Resumen: Con el objetivo de analizar el texto escrito como recurso didáctico aplicado en la enseñanza de la Educación Física y comprender las percepciones y prácticas construidas por profesores que utilizan ese recurso en sus clases, fueron entrevistados 21 maestros. Los participantes están convencidos de la importancia de esta intervención, seleccionan textos diversos y relacionados con temas actuales de la Educación Física, construyendo un proceso pedagógico coherente con lo que propone la literatura sobre el tema analizado. Así, se percibe que se preocupan con la contribución de la Educación Física para la construcción del lector, sin dejar de lado los conocimientos específicos del área.
*Instituto Federal de Educação Ciência e Tecnologia de São Paulo. São Paulo, SP, Brasil.

E-mail: pollyanebarros@hotmail.com

** Universidade São Judas Tadeu $e$ Universidade Presbiteriana Mackenzie. São Paulo, SP, Brasil.

E-mail: elisabetefreire@uol.com.br

***Universidade São Judas Tadeu. São Paulo, SP, Brasil.

E-mail: masgra@terra.com.br

Recebido em: 17-11-2014

Aprovado em: 01-07-2015

(c) (1) () Licence 


\section{INTRODUÇÃO}

A utilização do texto escrito como recurso para mediar o processo de aprendizagem é uma prática bastante antiga na área da Educação. M. A. Silva (2012) argumenta que já na Antiguidade livros e textos eram utilizados com fins educacionais. Geralmente, a presença do texto escrito na escola tem sido circunscrita ao livro didático (LD), o que tem dificultado a exploração adequada das potencialidades deste recurso. Choppin (2004) considera a definição do LD algo bastante complexo, diante da multiplicidade de formas adotadas e de funções desempenhadas por ele. Munakata (2012), embora reconheça essa complexidade, opta por apresentar sua característica geral: ser um livro produzido com o objetivo de facilitar o processo educacional. Para o autor, as primeiras iniciativas de elaboração desse tipo de livro são vistas já no século XIII, quando artesãos reproduziam livros manuscritos para a comercialização com estudantes universitários.

Nas últimas décadas, o LD tem atraído a atenção de vários pesquisadores (CHOPPIN, 2004), dando origem a debates e polêmicas. Diversas críticas têm sido apresentadas à sua utilização. A inflexibilidade na organização dos conteúdos, o uso mercantilista, os interesses ideológicos expressos nos livros e a interferência das políticas públicas adotadas são alguns dos aspectos criticados (ZABALA, 1998, MUNAKATA, 2012).

Apesar das críticas, o LD ainda prevalece entre os recursos empregados pelos professores em suas aulas (SILVA, M. A., 2012) e tem assumido formatos diversos. Algumas redes de ensino têm substituído o uso do LD tradicional pelo "sistema apostilado de ensino" (ADRIÃO et al., 2009), material didático elaborado pela própria rede, mas que mantém características muito semelhantes às do livro. Por isso mesmo, parte das críticas direcionadas ao LD podem também ser aplicadas aos sistemas apostilados. Esses sistemas começaram a ser utilizados no Brasil a partir da década de 1950 (MOTTA, 2001) e, durante muito tempo, foram comercializados por redes privadas de ensino.

Entretanto, nos últimos anos, iniciativas da rede pública de ensino também têm optado por utilizar os sistemas apostilados. Adrião et al. (2009, p. 802) investigaram, em municípios paulistas, a adoção desses sistemas de ensino elaborados a partir de parcerias com empresas privadas. Os autores identificaram:

[...] uma tendência crescente nos municípios paulistas, sobretudo naqueles com até 50 mil habitantes, considerados de pequeno porte, a buscar suporte político e pedagógico para 0 atendimento educacional sob sua responsabilidade junto a empresas privadas que oferecem serviços e produtos, tais como materiais didáticos para alunos e professores, incluindo apostilas e CDROMs, formação docente em serviço e monitoramento do uso dos materiais adquiridos.

Os gestores justificam a adoção desse material apontando a necessidade de uniformizar as práticas educacionais e construir uma identidade educacional para o município. Contudo, para Adrião et al. (2009) essa prática evidencia um retorno aos ideais tecnicistas adotados durante o período da ditadura militar. Além disso, essa é uma forma consentida de intervenção privada na rede pública de ensino, alinhada às características da política educacional brasileira e aos interesses internacionais, defendidos pelo Banco Mundial (ADRIÃO et al., 2009, MOTA JUNIOR; MAUÉS, 2014). 
A partir da década de 1990, a gestão da educação brasileira tem sido fortemente influenciada por organizações internacionais, a exemplo do que acontece em outros países da América Latina (ALTMANN, 2002). Mota Junior e Maués (2014) argumentam que essa iniciativa surge com a intenção de explorar economicamente a educação e, ao mesmo tempo, preparar trabalhadores que se adequem às novas demandas do mercado de trabalho. Fundamentandose em Altmann (2002), os autores afirmam que "no cerne das propostas do Banco Mundial para as reformas educacionais nos países periféricos, entre eles o Brasil, estavam a ênfase na educação básica, a descentralização da gestão e a centralização da avaliação dos sistemas escolares" (MOTA JUNIOR; MAUÉS, 2014, p. 1140).

Várias ações têm sido implementadas com a vigência dessa política educacional, como a inserção de diferentes sistemas e mecanismos de avaliação (Sistema Nacional de Avaliação da Educação Básica, Exame Nacional de Ensino Médio e Avaliação dos Cursos Superiores) e a elaboração dos Parâmetros Curriculares Nacionais (ALTMANN, 2002). 0 estabelecimento de parcerias público-privadas e o incentivo ao uso do livro didático ou de sistemas apostilados de ensino também são exemplos de ações que permitem a concretização dos objetivos propostos pelas organizações internacionais. Assim, a iniciativa privada se beneficia com a exploração econômica potencializada pela comercialização do material a ser utilizado pelos alunos, ao mesmo tempo em que se influencia a configuração do currículo escolar (CUNHA, 2011).

Como resultado dessa política educacional, o uso do livro didático ou de sistemas apostilados pode ser visto em diversas escolas brasileiras. Nas Secretarias de Educação dos estados de São Paulo, Rio Grande do Sul e do Paraná, por exemplo, esse tipo de material tem sido elaborado com a intenção de orientar a prática pedagógica a ser adotada e apresentar textos didáticos para utilização dos estudantes. Esta realidade atinge a Educação Física (EF), já que referenciais específicos para a área têm sido elaborados e utilizados, tanto na rede pública, quanto na rede privada de ensino (AMARAL, 2014, DARIDO et al., 2010).

Neste contexto, alguns professores vêm enfrentando a tarefa, muitas vezes obrigatória, de utilizar o texto escrito em suas aulas. Um exemplo dessa obrigatoriedade pode ser visto na aplicação da Proposta Curricular do Estado de São Paulo (SÃO PAULO, 2010). Para sua efetivação, foram elaborados cadernos didáticos a serem utilizados por professores e estudantes, em cada área do currículo escolar. Como apresentado por participantes na pesquisa elaborada por Freitas (2011), algumas escolas têm exigido do professor a utilização desse material, exigência justificada pela possibilidade de que a aprendizagem dos conteúdos apresentados seja exigida dos estudantes quando se submeterem ao Sistema de Avaliação de Rendimento Escolar do Estado de São Paulo (SARESP).

Durante muito tempo, a utilização do texto escrito nas aulas nas aulas de EF era algo raro. Os recursos didáticos utilizados nas aulas de EF pareciam estar restritos aos implementos esportivos (bolas, arcos, rede, traves, dentre outros), isto é, recursos ligados à aprendizagem de habilidades motoras. Esse diagnóstico foi apresentado nos Parâmetros Curriculares Nacionais Ensino Médio, como apresentado no trecho apresentado a seguir:

Enquanto as demais áreas de estudo dedicam-se a aprofundar os conhecimentos dos alunos, através de metodologias diversas, estudos do meio, exposição de vídeos, apreciação de obras de diversos autores, leituras de textos, solução de problemas, discussão de assuntos atuais e concretos, as aulas do "mais atraente" dos componentes limita-se aos já conhecidos fundamentos do esporte e jogo. (BRASIL, 2000, p. 33; destaque no original) 
A utilização do livro didático e de sistemas apostilados de ensino pode ser um dos fatores a influenciar a mudança dessa realidade apontada em Brasil (2000). Porém, o uso desse material tem merecido críticas diversas. A falta de preparação do professor (CASTELLANI, 2013) é um entre tantos outros fatores que podem prejudicar a qualidade do trabalho realizado e desestimular sua aplicação. Cordeiro (2004) explica que livro didático e sistemas apostilados, em geral, empregam textos escritos fragmentados e superficiais, que limitam as possibilidades de interação e interpretação do leitor (CORDEIRO, 2004). Para Campos e Montoito (2010), esse material apresenta uma reduzida variabilidade dos gêneros textuais. Nessa perspectiva, os autores defendem a utilização de outros textos escritos, como alternativa ao LD, como, por exemplo: textos de divulgação científica, livros de literatura, poesia, artigos de jornais e revistas, entre outros.

Cordeiro (2004) e Mendes (2008) explicam que o contato com diferentes gêneros textuais é importante para estimular no estudante a construção de competência para a leitura, objetivo que deve orientar o trabalho realizado, segundo a Secretaria Municipal de Educação da cidade de São Paulo (SÃO PAULO, 2006a). Estariam os professores de EF (e de outras áreas) preparados para desempenhar a tarefa de estimular a construção da competência leitora?

As contribuições da EF para a construção da competência leitora e escritora são analisadas pela Secretaria Municipal de Educação da cidade de São Paulo (SÃO PAULO, 2006b), a partir da abordagem cultural. Considerando a cultura corporal como objeto de estudo a ser compreendido na EF Escolar, os autores acreditam na possibilidade de estimular a "leitura e interpretação do gesto, do movimento humano, do signo cultural constituinte dos diversos grupos que compõem a sociedade atual" (SÃO PAULO, 2006b, p. 19). Nessa perspectiva, a EF deve possibilitar, durante suas aulas, a análise de diferentes textos (verbais ou não verbais). Entre esses textos, o texto escrito também merece a atenção do professor.

Cordeiro (2004) lembra que a leitura, na atualidade, assume características distintas, permitindo ao leitor comunicar-se de diferentes modos, seja para obter informações e ressignificá-las, com a intenção de atender a necessidades de seu exercício profissional, seja para criar um espaço que permita afastar-se do trabalho e de sua realidade, em momentos destinados ao lazer. Nesta dinâmica atual, é papel da escola, e da EF, propiciar ao estudante 0 contato com textos escritos diversos que possam atender aos seus desejos pessoais.

Concordando com a autora, entendemos que o trabalho com o texto escrito permite estimular a análise e reflexão do leitor, levando à ampliação de seus "horizontes e expectativas" (CORDEIRO, 2004, p. 99). Sua relevância é apontada também por Campos e Montoito (2010, p. 159), ao analisarem a utilização do texto no ensino de Ciências e Matemática. Para os autores, o texto escrito pode estimular a "imaginação e a afetividade na construção de ideias, conceitos e visões de mundo e, portanto, de ciência". Assim, a utilização do texto escrito nas aulas de EF, bem como a oferta de recursos didáticos e metodologias diversas, pode contribuir para estimular nos alunos a reflexão e a imaginação, ampliando as situações de aprendizagem relacionadas à cultura corporal de movimento.

Nessa perspectiva, a utilização de livros infantis pode ser um recurso interessante para apresentar novos jogos e brincadeiras aos alunos da Educação Infantil. Histórias que apresentem personagens envolvidos nessas atividades podem estimular a curiosidade e a criatividade das crianças. 0 uso do texto pode trazer contribuições para a reflexão sobre temáticas diversas, como aquelas apresentadas nos Parâmetros Curriculares Nacionais 
(BRASIL, 1998), por exemplo. Assim, a leitura de textos veiculados em revistas ou jornais pode provocar debates sobre os padrões de beleza apresentados pela mídia, o doping no esporte ou as relações de gênero no futebol. Por isso mesmo, em nome da crítica ao livro didático e ao sistema apostilado, não se podem descartar as contribuições do texto escrito para a aprendizagem na EF.

Mas, como qualquer outro recurso didático, a utilização do texto deve ser orientada pelos objetivos que se procura atingir. A concepção de EF que tem sido adotada pelos professores é um fator que pode dificultar seu emprego nas aulas (BRASIL, 2000). Assim, quando o professor concebe a EF como espaço para o desenvolvimento exclusivo da aptidão física e/ou para a aprendizagem de técnicas esportivas, o texto escrito pode ser um recurso pouco adequado. Contudo, sua relevância torna-se evidente quando uma tendência pedagógica crítica (BRACHT, 1999) orienta as escolhas feitas pelo professor, já que será necessário criar situações diversificadas de aprendizagem, diferentes daquelas tradicionalmente utilizadas quando se busca a aprendizagem de habilidades motoras específicas de determinadas modalidades esportivas.

Se a EF for entendida como a área do currículo responsável por possibilitar ao estudante conhecer, vivenciar e compreender a cultura corporal de movimento, estimulando a análise crítica da realidade e contribuindo para a construção de sua autonomia, será necessário buscar a diversificação de recursos didáticos. Esta ideia é defendida por Brasil (1998, p. 85), quando se afirma que criar situações que facilitem o "acesso a livros, revistas, jornais e vídeos; a elaboração de pesquisas, entrevistas, painéis, visitas, apreciação e organização de eventos e produção de materiais" pode contribuir para o processo de construção da autonomia do estudante.

No entanto, a utilização desse recurso exige uma ação planejada (CORDEIRO, 2004). Para que o professor possa construir esse planejamento é preciso que haja um processo de formação profissional (inicial e continuada). A Secretaria Municipal de Educação de São Paulo tem investido nesse processo e preparou o Referencial de Expectativas para o Desenvolvimento da Competência Leitora e Escritora (SÃO PAULO, 2006a). No documento são apresentadas orientações para que os professores possam mediar o contato dos alunos com os textos. Iniciativas como essa podem influenciar alguns professores de EF a utilizar o texto escrito em suas aulas, de forma voluntária. Conhecer como os professores têm utilizado esse recurso didático pode nos ajudar a compreender suas possibilidades e limites.

A partir do exposto, entendemos que alguns professores de EF estão trazendo o texto escrito para suas aulas, seja por iniciativa própria ou por imposição da rede de ensino em que atuam. Partindo desse pressuposto, podemos nos questionar: o que pensam esses professores sobre a utilização do texto como recurso didático? Como eles têm utilizado o texto nas aulas? Qual sua percepção sobre o trabalho que realizam?

Infelizmente, os poucos estudos existentes sobre o tema não têm se dedicado a responder a essas questões. Alguns deles têm focalizado a compreensão das possibilidades de aplicação do livro didático na EF como meio para a organização curricular, como Darido et al. (2008), Galatti, Paes e Darido (2010) e Diniz e Darido (2012). Darido et al. (2008) apresentam os pressupostos que orientaram a elaboração de um livro didático para a Educação Física. Eles reconhecem a existência de críticas e limitações presentes na utilização do livro didático, mas acreditam na sua relevância para a área e discutem algumas possibilidades de sua utilização. 
Galatti, Paes e Darido (2010) construíram um livro que apresenta sequências didáticas para abordar os Jogos Esportivos Coletivos nas aulas. Sugestões para a elaboração de um livro didático para o ensino da dança nas aulas de Educação são apresentadas por Diniz e Darido (2012).

Outras pesquisas se dedicam a elaborar e avaliar a utilização de LD. É o que observamos em Rodrigues e Darido (2011), que elaboraram um LD da modalidade basquetebol e avaliaram as vantagens e desvantagens da aplicabilidade do material junto a cinco professores de EF. Já Rufino e Darido (2013) avaliaram a implementação de um livro de EF sobre o tema transversal saúde, sob a perspectiva de 33 alunos da rede pública.

Outro estudo sobre o LD foi apresentado por Botelho e Neira (2014). Os autores realizaram uma pesquisa documental sobre estudos publicados no Brasil e na Espanha que se dedicaram a investigar o LD. Os autores verificaram que os estudos realizados evidenciam a presença de imagens e textos que expressam crenças estereotipadas, preconceituosas e discriminatórias nos livros da área.

É possível verificar que os estudos apresentados acima se dedicaram a olhar para o LD e não o texto escrito. Dessa forma, pouco contribuem para o entendimento do texto como recurso didático, suas contribuições e forma de utilização. Encontramos autores que defendem o uso do texto, como Paula (2003) e Carmo (1999). Paula (2003) discute a utilização de apoio bibliográfico como recurso metodológico para o ensino da EF nos níveis fundamental e médio de escolarização. Carmo (1999) propõe o uso do livro no ensino do futebol e discute a importância de se incluir material escrito aos demais recursos tradicionalmente presentes. No entanto, esses autores não investigaram como o texto escrito tem sido utilizado pelo professor. Partindo desta problemática, realizamos o presente estudo com os objetivos de analisar 0 texto escrito como recurso didático aplicado no ensino da EF e compreender as percepções e práticas construídas por professores que utilizam esse recurso em suas aulas. Acreditamos que identificar experiências e percepções de professores que utilizam o texto escrito pode contribuir para compreender melhor a prática pedagógica do professor, identificando avanços, possibilidades e necessidades na utilização desse recurso didático no contexto da EF.

\section{PERCURSO METODOLÓGICO}

Para atingir os objetivos propostos, realizamos uma pesquisa qualitativa, buscando interpretar e analisar significados e perspectivas dos participantes sobre o contexto a ser investigado (TRIVIÑOS, 1987). Para isso, entendemos que seria necessário selecionar uma amostra intencional e por conveniência, constituída por professores que apresentassem como característica específica o uso intencional e voluntário do texto escrito. Assim, participaram do estudo 21 professores, vinculados às redes privada e pública de ensino do estado de São Paulo, que utilizam o texto escrito como recurso didático em suas aulas há pelo menos um ano.

A entrevista semiestruturada foi escolhida como instrumento para obter acesso às percepções e descrições e explicações apresentadas pelos participantes sobre o objeto de estudo (LAVILLE; DIONNE, 1999, FLICK, 2004). Além da entrevista, optamos por utilizar como fonte de informação textos escritos fornecidos pelos próprios participantes, para exemplificar o material que eles têm utilizado. Consideramos que conhecer alguns dos textos utilizados nos permitiria compreender melhor as concepções e experiências descritas pelos participantes. 
Para analisar as informações obtidas nas entrevistas e nos textos fornecidos, utilizamos a técnica de análise de conteúdo. Este tipo de análise, proposto por Bardin (2011), tem sido bastante aplicado em estudos qualitativos e permite a exploração de mensagens e informações para compreender, mais profundamente, os fenômenos que se propõe investigar (MORAES, 1999).

Optamos por solicitar aos participantes a indicação de nomes fictícios a serem utilizados durante a apresentação dos resultados. Os nomes apresentados são fictícios e respeitam as sugestões dos participantes. Os procedimentos de pesquisa foram submetidos ao Comitê de Ética em Pesquisa, conforme processo CAAE no. 24914813.6.0000.0089, tendo parecer aprovado número 470.038 .

\section{O TEXTO ESCRITO NO CONTEXTO DA EF: INTERPRETANDO A PERCEPÇÃO DOS PROFESSORES}

A maior parte dos participantes (12) atua em escolas há aproximadamente cinco anos, têm entre 25 e 42 anos de idade e 12 são do sexo masculino. Treze participantes cumprem uma carga horária semanal superior a 40 horas, atuando em duas ou mais instituições. Onze professores atuam apenas no ensino fundamental, enquanto seis estão no ensino fundamental e médio.

No tocante à formação profissional, inicial ou continuada, observamos que se trata de um grupo em constante qualificação, seja pela busca de uma segunda graduação, seja pela procura de cursos de especialização nos âmbitos lato e stricto sensu. Assim, 13 docentes fizeram especialização lato sensu; oito já concluíram curso de mestrado; dois e quatro, respectivamente, estão com os cursos de mestrado e doutorado em andamento.

Apenas três dos entrevistados atuam, unicamente, na rede privada de ensino. Deles, somente um professor revelou ter horário de planejamento ou reunião coletiva semanal, os demais indicaram a existência de um encontro de planejamento coletivo entre os professores, que, normalmente, é realizado na semana anterior ao início das aulas de cada semestre. Já os professores da rede pública de ensino têm, na sua jornada de trabalho, uma carga horária semanal destinada ao planejamento individual e às reuniões com os demais professores. Essa carga horária varia entre 2h/a e 14h/a, a depender da carga horária total do professor. Outra característica peculiar desses docentes é que oito já viveram a experiência de assumir cargos de gestão (diretorias de ensino, coordenação ou supervisão) e seis já atuaram com assessoria pedagógica e com a formação de professores das redes de ensino a que estão vinculados.

Quinze professores declaram utilizar textos escritos em suas aulas desde que ingressaram no magistério. Os demais professores começaram a utilizá-los durante o percurso de sua intervenção. Vários fatores foram responsáveis por despertar o interesse por sua utilização, declararam os professores. Entre eles, está a influência da formação profissional, a busca por metodologias diversificadas para o ensino da EF e a necessidade de adequar-se à estrutura física da escola.

A influência da formação profissional, em especial da formação continuada, é percebida por vários participantes, como Maria e Beatriz. Elas afirmam: 
[...] talvez pela minha formação... logo quando eu formei... eu tive assim uma grande contribuição dos cursos de extensão que eu fazia na faculdade de Educação (Maria).

Como a minha formação já foi dada numa perspectiva mais crítica, sempre, o trabalho com texto fez sentido para mim (Beatriz).

Embora os professores percebam a influência da formação profissional no trabalho que realizam, não relatam ter passado por experiências, durante seu curso de graduação, em que a utilização dos textos na escola tenha sido analisada. Pedro explica que observava a forma como os docentes universitários utilizavam o texto e se inspirou nesses docentes. Assim como ele, é possível que outros professores adotem essa prática. Entretanto, nem sempre a forma como o texto é utilizado no ensino superior é adequada para a utilização na educação básica.

A participação em cursos de extensão universitária e em grupos de estudos também foi mencionada por alguns professores, assim como o contato com determinadas propostas curriculares ou currículos oficiais. Edson, por exemplo, afirma que, ao ingressar na rede de ensino do município de São Paulo, tomou contato com uma forma de pensar e com referenciais (SÃO PAULO, 2006a, SÃO PAULO, 2006b) que the estimularam a olhar o texto escrito como alternativa viável e começou a utilizá-lo em suas aulas.

Diante dessa nova demanda apresentada aos professores de EF, entendemos que a formação inicial e continuada deve prever o estímulo e a orientação para utilização e elaboração desse tipo de recurso. É preciso compreender que "a construção de uma leitura autônoma requer o planejamento de situações didáticas em que os alunos possam realmente ler diversos tipos de texto, com diferentes intenções e funções, e exercitar as habilidades específicas para a leitura compreensiva de textos reais, sejam ou não escolares" (SÃO PAULO, 2006b, p. 9).

A necessidade de diversificar os recursos didáticos utilizados nas aulas foi outro fator citado pelos professores. Eles argumentam sobre a importância de oferecer ao aluno 0 acesso a diferentes fontes de informação e, consequentemente, a diferentes discursos. Identificamos, também, que alguns professores declaram ter iniciado o uso de textos com a intenção de fundamentar o trabalho que realizam, explicitando que sua intervenção se respalda em referências científicas ou em argumentos de autoridade, isto é, opiniões de especialistas em determinado assunto.

A opção por utilizar uma determinada forma de intervenção e um recurso específico, como o texto escrito (ZABALA, 1998; SÃO PAULO, 2006a), será orientada por uma série de decisões anteriores, que definem, por exemplo, os objetivos a serem atingidos nas aulas. Os três objetivos que orientam as escolhas dos participantes são apresentados no Quadro 1.

Quadro 1 - Objetivos explicitados pelos professores para o uso do texto escrito

\begin{tabular}{|l|l|}
\hline \multicolumn{1}{|c|}{ Objetivos } & \multicolumn{1}{c|}{ Nome dos Professores } \\
\hline $\begin{array}{l}\text { Analisar e refletir sobre os conhecimentos e sobre a } \\
\text { Cultura Corporal de Movimento }\end{array}$ & $\begin{array}{l}\text { Douglas, Rodrigo, Roberto, Beatriz, Adenor, Edson, Daniela, } \\
\text { André, Maria, Luciana, Alex, Eduardo, Pedro. }\end{array}$ \\
\hline $\begin{array}{l}\text { Aprender e aprofundar conhecimentos sobre a Cultura } \\
\text { Corporal de Movimento }\end{array}$ & $\begin{array}{l}\text { André, Daniela, Fabiana, Alex, Roberto, Beatriz, Eduardo, } \\
\text { Adalberto, Rodrigo, Mário, Rafaela, Douglas, Vera, Francisca, } \\
\text { Adenor, CBC, Pedro. }\end{array}$ \\
\hline Construir a competência para a leitura e a escrita & André, Daniela, Vera e Pedro. \\
\hline
\end{tabular}


A partir da utilização do texto escrito, os professores esperam que os alunos analisem criticamente a cultura corporal de movimento e compreendam aspectos porvezes negligenciados no pensamento de senso comum. Destacamos, a seguir, excertos das entrevistas que tratam deste objetivo.

[...] é mais um instrumento para levar os alunos a refletir sobre alguma coisa. Então, é um instrumento, e eu utilizo simplesmente como, "simplesmente"!!! É uma coisa tão grande até... mas como um instrumento para levá-los a refletir sobre algo (Maria).

Então, você conseguir mudar a ideia do aluno e fazer com que ele enxergue o outro lado. Além da sua voz, você tem que mostrar outros documentos que acabam validando a sua fala. Aí quando o aluno tem contato com outro material diferente, que não é a fala do professor, como o texto, seja o vídeo, seja imagens, ele começa a repensar aquilo que ele já conhece (Rodrigo).

Cordeiro (2004) argumenta que o texto escrito pode estimular a construção de novas leituras da realidade e de conceitos, como propõem os professores participantes nesta pesquisa. Além disso, o texto escrito é, também, um recurso para acesso a informações e construção de conhecimento. Esse é outro objetivo declarado pelos professores, quando utilizam o texto escrito. Eles argumentam que esse uso permite aos estudantes conhecer as manifestações da cultura corporal de movimento, identificar os conhecimentos prévios e analisar o tema escolhido de forma mais ampliada e aprofundada.

Contribuir para o processo de formação do leitor é outro objetivo citado por alguns professores. Cordeiro (2004) argumenta que a preparação do leitor é responsabilidade de todo educador, não podendo ser assumida apenas pelo professor de Português. A EF pode contribuir para esse processo, sem deixar de lado sua especificidade. Nessa perspectiva, Neves (1999) e São Paulo (2006a) argumentam que o professor deve ver o movimento humano como um texto a ser lido. A compreensão leitora envolve não apenas a capacidade de decodificação de palavras, mas, também, a compreensão dos significados, dos sentidos, da função do texto. Desse modo, o texto escrito também pode ser uma estratégia utilizada para ampliar e aprofundar a compreensão do movimento, entendido como uma forma de linguagem (SÃO PAULO, 2006b).

A partir dos objetivos que orientam o uso do texto escrito é possível compreender elementos da concepção de EF que tem orientado os professores. Destaca-se a intencionalidade de preparar os estudantes para conhecer, compreender e transformar a cultura corporal de movimento e analisar criticamente a EF e a sociedade. É possível perceber a influência das propostas críticas, identificadas por Bracht (1999) e defendidas nos Parâmetros Curriculares Nacionais (BRASIL, 1998), nos objetivos declarados pelos participantes.

Uma das primeiras etapas do trabalho com texto escrito é a seleção daqueles que serão utilizados. Os participantes apresentaram diferentes critérios para selecionar um texto para aplicação nas aulas. Um dos critérios adotados é a extensão do texto. Alguns deles afirmam selecionar textos curtos, especialmente para utilização com estudantes mais novos, como Maria e Beatriz. Outros relatam selecionar textos maiores para uso com alunos dos anos finais do ensino fundamental ou do ensino médio. Interessante notar, no entanto, que os textos fornecidos pelos professores, independentemente do nível de ensino em que são aplicados, apresentam variados tamanhos. 
Confiabilidade e origem do texto constituem outro critério apresentado pelos participantes. Eles relatam preocupar-se com a qualidade da escrita, uma vez que observam o teor científico das informações, assim como a confiabilidade do autor e do suporte no qual o texto é disponibilizado (site, revista, jornal, livros). André explica sua escolha:

Olha, eu escolho o material didático pela seriedade de quem está escrevendo [...] Porque, com uma formação política que eu tenho, tenho que mostrar para meu aluno e politizar ele também. Eu não vou trazer um texto didático de uma pessoa que é ingênua ou que está analisando a realidade de uma forma que não dá né? (André).

Com certeza, o professor deve escolher cuidadosamente 0 texto a ser utilizado (CORDEIRO, 2004, SÃO PAULO, 2006a). Contudo, se a intenção do professor for estimular a reflexão dos estudantes, apresentar um texto com informações incorretas ou pouco confiáveis pode ser uma estratégia adequada. Nesse sentido, comparar diferentes textos e diferentes gêneros textuais é importante, já que o estudante terá contato com diferentes textos em seu cotidiano. O próprio André reconhece essa importância quando afirma desejar que os estudantes questionem algumas informações apresentadas na televisão.

Outro critério utilizado pelos professores é a adequação de vocabulário e linguagem apresentada. De acordo com a faixa etária e, consequentemente, com o nível de ensino dos alunos, há uma variação na exigência do vocabulário (termos mais ou menos técnicos), bem como na linguagem (mais ou menos rebuscada). Alguns professores destacam valorizar a utilização de uma linguagem científica e mais rebuscada. Outros optam por textos com linguagem mais simplificada. $O$ mais relevante é que o texto escolhido atenda às necessidades dos estudantes, diagnosticadas pelos professores (CORDEIRO, 2004, SÃO PAULO, 2006a).

As necessidades e interesses apresentados pelos estudantes, assim como a possibilidade de atratividade do material utilizado, são outros critérios apresentados. Como explica Cordeiro (2004), para estimular a formação de leitores é importante construir práticas que sejam agradáveis. Dessa forma, adequar a temática do texto aos interesses dos estudantes, buscar um vocabulário compreensível e desafiador, como fazem os professores, torna a experiência mais significante.

Ao longo da sua escolarização é importante que o estudante tenha contato com uma variedade de textos, de gêneros, tipos e suportes diferentes. Isso permitirá que ele vivencie procedimentos de leitura diversificados e distintos modos de ler, além de desenvolver as próprias estratégias de leitura (SÃO PAULO, 2006b, MENDES, 2008). Nesse sentido,

[...] várias modalidades de leitura podem ser utilizadas, em diferentes situações, diante de um mesmo tipo de texto: é possível ler um material informativo-científico para obter uma informação global, para buscar um dado específico ou para aprofundar determinado aspecto do tema; a leitura de um artigo de jornal pode ser feita em um momento simplesmente por prazer e em outro como objeto de reflexão; um poema ou um conto podem ser lidos primeiro por prazer e depois como forma de comunicar algo a alguém; enfim, há muitas possibilidades de abordagem dos textos (SÃO PAULO, 2006b, p. 10).

Marcuschi (2008) explica que os textos podem ser classificados em tipos, de acordo com sua natureza linguística. São exemplos de tipos de textos: a narrativa e a descrição. Já os gêneros textuais expressam conteúdos, propriedades funcionais, estilo e composição característica. Escritos ou orais, eles são quase ilimitados (MARCUSCHI, 2008), especialmente 
em decorrência das novas tecnologias de comunicação e informação (MENDES, 2008). Alguns exemplos de gêneros são: telefonema, bilhete, aula expositiva, receita, resenha, entre outros.

Analisamos os textos fornecidos pelos professores e as informações apresentadas nas entrevistas para identificar os gêneros textuais apresentados. Os gêneros identificados aparecem no quadro abaixo:

Quadro 2 - Gêneros textuais utilizados pelos professores

\begin{tabular}{|l|l|}
\hline \multicolumn{2}{|l|}{ Gêneros Textuais Utilizados } \\
\hline - Didáticos & $\begin{array}{l}\text { Maria, Edson, Luciana, Alex, Roberto, Pedro, Rodrigo, Mario, Rafaela e } \\
\text { Douglas. }\end{array}$ \\
\hline Livros didáticos & André, Fabiana, Eduardo e Alberto. \\
\hline • Didatizados & \multicolumn{2}{|l|}{} \\
\hline Charge & Maria e André. \\
\hline Tirinhas & Vera e Adenor. \\
\hline História em quadrinhos & Francisca, Rafaela e Eduardo \\
\hline Textos jornalísticos & $\begin{array}{l}\text { Maria, André, Edson, Luciana, Fabiana, Francisca, Adenor, Alex, Beatriz, } \\
\text { Eduardo, Alberto, Pedro, Adalberto e Mário. }\end{array}$ \\
\hline Textos acadêmicos & $\begin{array}{l}\text { André, Daniela, Edson, Luciana, Adenor, Roberto, Beatriz, Alberto e } \\
\text { Rafaela. }\end{array}$ \\
\hline Poema & Roberto. \\
\hline Poesia & Adenor . \\
\hline Letra de música & Adenor, Beatriz, Eduardo, Mário e Edson. \\
\hline Crônicas & Beatriz . \\
\hline Texto do aluno & André. \\
\hline Texto elaborado pelo professor & $\begin{array}{l}\text { André, Luciana, Fabiana, CBC, Adalberto, Pedro, Maria, Francisca, } \\
\text { Daniela, Vera, Adenor, Douglas e Rafaela. }\end{array}$ \\
\hline
\end{tabular}

Fonte: Elaborado pelas autoras

Os textos didáticos compreendem os gêneros textuais elaborados com a finalidade de mediar o processo de aprendizagem. Segundo Silva et al. (2011) são aqueles que já passaram pelo processo de didatização. Já os didatizados compreendem os gêneros textuais cuja finalidade inicial não é pedagógica, isto é, não foram elaborados para mediar o processo de aprendizagem. Para os autores, os textos didatizados são aqueles selecionados pelo professor para serem levados para a sala de aula e "didatizados" pela primeira vez com a proposta de trabalho apresentada pelo professor.

Os gêneros textuais podem ser apresentados em diferentes suportes (MARCUSCHI, 2008). O suporte é toda superfície física na qual o texto pode ser fixado e, consequentemente, disponibilizado. De acordo com Marcuschi (2008) os suportes podem ser convencionais (livro, livro didático, jornal, revistas, rádio, televisão, telefone, quadro de avisos, outdoor, encarte, folder, luminosos, faixas) ou incidentais (embalagens, para-choques e para-lamas de caminhão, roupas, paredes, muros, paradas de ônibus, estação de metrô, calçadas, fachadas, janelas de ônibus e corpo humano). Com base nas declarações dos docentes, foi possível identificar que os principais suportes por meio dos quais os alunos têm acesso ao texto são: material impresso (14), lousa (2), meio eletrônico (1), jornais e revistas (14). 
Podemos verificar que o grupo de professores que participou deste estudo tem trabalhado com diferentes gêneros textuais e suportes, desenvolvendo trabalho coerente com as recomendações apresentadas na literatura. Esse trabalho é importante, pois cada texto estabelece um elo diferente com o leitor, elo influenciado pelo tipo, gênero ou suporte utilizado. As relações entre leitor-texto e escritor-texto estabelecem-se como num jogo cujas regras modificam-se através dos pactos estabelecidos entre os participantes (MENDES, 2008).

Procuramos compreender como o professor utiliza o texto em suas aulas. Quanto ao espaço em que é utilizado o texto, o local mais citado pelos participantes foi a sala de aula, na qual os alunos passam a maior parte do tempo. Apenas quatro professores revelaram utilizar outros espaços (biblioteca, sala de leitura, pátio, quadra esportiva). Quanto à dinâmica adotada, os professores descrevem atividades com agrupamentos diferenciados, envolvendo atividades individuais, em pequenos grupos, em grandes grupos ou com a turma toda. Além disso, relatam situações diversas, com leituras orais ou silenciosas, por vezes realizadas coletivamente. Para Azambuja e Souza (1995) as atividades de leitura podem ser feitas individual ou coletivamente, oral ou silenciosamente. A leitura oral, por exemplo, é interessante para pequenos textos e pode propiciar o treino expressivo da leitura, estimular a formação de bons leitores e ouvintes, além da interação leitor-texto-ouvinte.

Ao refletirem sobre o trabalho que realizam, os professores avaliaram positivamente as experiências construídas. Justificam essa avaliação a partir de vários argumentos. A melhora qualitativa na aprendizagem, o maior interesse ou menor resistência à atividade com texto, além de mudanças na concepção de Educação Física são alguns dos resultados observados nos estudantes e considerados relevantes pelos professores. Alguns não mencionam resultados, mas consideram a utilização do texto positiva, apenas por acreditar em sua importância, seja para o aluno, seja para a organização do trabalho do professor. Dois professores acreditam que o trabalho pode atingir de forma diferente cada estudante, sendo difícil fazer uma avaliação. De qualquer modo, eles acreditam na importância do trabalho, mas não consideram possível mensurar os resultados obtidos.

Ainda que os professores se declarem satisfeitos com o trabalho realizado, percebemos que há uma análise crítica constante. Alguns declaram que as atividades propostas nem sempre se mostram adequadas, sendo necessário rever sua aplicação. Além disso, os participantes explicitam o enfrentamento de algumas dificuldades, como a ausência de infraestrutura para a aplicação do recurso, problema que afeta vários professores, ainda que não utilizem 0 texto escrito. De acordo com Santini e Molina Neto (2005) e Gaspari et al. (2006), espaços inadequados e falta de materiais, aspectos apontados pelos participantes neste estudo, são dificuldades enfrentadas por vários professores. Outras dificuldades citadas pelos professores são a resistência demonstrada por alguns estudantes, diante da concepção de EF existente e a falta de tempo para o planejamento das atividades a serem aplicadas.

\section{CONSIDERAÇÕES FINAIS}

Ao realizar este estudo pudemos perceber que os professores que utilizam voluntariamente o texto escrito em suas aulas acreditam na relevância dessa intervenção, e selecionam textos diversificados e relacionados com temáticas atuais da Educação Física, construindo um processo pedagógico coerente com o que propõe a literatura sobre a temática 
analisada. Assim, percebemos que eles se preocupam com a contribuição da Educação Física para a construção do leitor, sem deixar de lado os conhecimentos específicos da área.

Acreditamos que o uso do texto escrito na EF pode contribuir para que os alunos construam conhecimentos significantes sobre a cultura corporal de movimento, como propõem os Parâmetros Curriculares Nacionais. Esses conhecimentos podem contribuir para que sejam atingidos os objetivos propostos pela escola e pela EF. Os professores participantes confirmam esta crença e evidenciam possibilidades de sua utilização. Assim, a partir dos resultados aqui apresentados, é possível que outros professores sintam-se estimulados a utilizar esse recurso em suas aulas.

Os professores apresentaram alguns procedimentos didáticos adotados, mas a complexidade do cotidiano do professor não pode ser expressa apenas a partir das declarações. Assim, as informações apresentadas não permitiram compreender como a aplicação acontece nas aulas. Eles mencionam que há uma resistência dos estudantes quando o processo de utilização do texto tem início e que essa resistência diminui com o prolongamento de sua utilização. Contudo, para compreender como os alunos reagem e aproveitam as atividades, seria necessário realizar outros estudos.

\section{REFERÊNCIAS}

ADRIÃO, Theresa; GARCIA, Teise; BORGHI, Raquel; ARELARO, Lisete. Uma modalidade peculiar de privatização da educação pública: a aquisição de "sistemas de ensino" por municípios paulistas. Educação e Sociedade, Campinas, v. 30, n. 108, p. 799-818, out. 2009.

AMARAL, Lucas Vieira. Textos didáticos na prática pedagógica do professor de educação física da rede estadual de ensino de Pernambuco: possibilidades, limites e contribuições. 2014. 161 f. Dissertação (Mestrado em Educação Física) - Escola Superior de Educação Física, Universidade de Pernambuco, Recife, 2014.

ALTMANN, Helena. Influências do Banco Mundial no projeto educacional brasileiro. Educação e Pesquisa, São Paulo, v. 28, n. 1, p. 77-89, jan./jun. 2002.

AZAMBUJA, Jorcelina Queiroz; SOUZA, Maria Letícia Rocha de. O estudo do texto como técnica de ensino. In: VEIGA, IIma Passos Alencastro - (Org.). Técnicas de ensino: por que não? 3. ed. Campinas: Papirus, 1995.

BARDIN, Laurence. Análise de conteúdo. São Paulo: Edições 70, 2011.

BOTELHO, Rafael Guimarães; NEIRA, Marcos Garcia. Análisis de libros de texto en Brasil y em España: una introducción al tema en el área de Educación Física. Movimento, Porto Alegre, v. 20, n. 2, p. 659-685, abr./jun. 2014.

BRACHT, Valter. A constituição das teorias pedagógicas da educação física. Cadernos Cedes, Campinas, v. 19, n. 48, p.69-78, ago. 1999.

BRASIL. Secretaria de Educação Fundamental. Parâmetros curriculares nacionais: Educação Física. Brasília : MEC/SEF, 1998. 
BRASIL. Secretaria de Educação Média e Tecnológica. Parâmetros curriculares nacionais ensino médio. Brasília: Secretaria de Educação Média e Tecnológica/MEC, 2000. Pt. 2 Linguagem, Códigos e suas Tecnologias.

CAMPOS, Raquel Sanzovo Pires; MONTOITO, Rafael. O texto alternativo ao livro didático como proposta interdisciplinar do ensino de ciências e matemática. In: PIROLA, Nelson Antônio. (Org.). Ensino de ciências e matemática. São Paulo: Editora UNESP; 2010. Pt. 4: temas de investigação. p. 157-174. Disponível em: <http://books.scielo.org>. Acesso em: 17 mar. 2015.

CARMO, Sérgio Carnevale. O livro como recurso didático no ensino do futebol. 1999. $121 \mathrm{f}$. Dissertação (Mestrado em Educação Física) - Faculdade de Educação Física, Universidade de Campinas, Campinas, 1999.

CASTELLANI, Rafael Moreno. A nova proposta curricular do estado de São Paulo: limites e virtudes. Conexões, Campinas, v. 11, n. 1, p. 235-251, jan./mar., 2013.

CHOPPIN, Alain. História dos livros e das edições didáticas: sobre o estado da arte. Educação e Pesquisa, São Paulo, v. 30, n. 3, p. 549-566, set./dez. 2004.

CORDEIRO, Verbena Maria Rocha. Itinerários de leitura no espaço escolar. Revista da FAEEBA: Educação e Contemporaneidade, Salvador, v. 13, n. 21, p. 103-118, jan./jun, 2004.

CUNHA, Luiz Antônio. Contribuição para a análise das interferências mercadológicas nos currículos escolares. Revista Brasileira de Educação, Rio de Janeiro, v. 16, n. 48, p. 585-607, set.-dez., 2011.

DARIDO, Suraya Cristina et al. A construção de um livro didático na educação física escolar: discussão, apresentação e análise. In: PINHO, Sheila Zambello de; SAGLIETTI, José Roberto Corrêa (Org.). Núcleos de ensino. São Paulo: Unesp, 2008. p. 387-409.

DINIZ, Irla Karla dos Santos; DARIDO, Suraya Cristina. Livro didático: uma ferramenta possível de trabalho com a dança na Educação Física Escolar. Motriz, Rio Claro, v. 18, n. 1, p. 176-185, jan./mar. 2012.

FLICK, Uwe. Uma introdução à pesquisa qualitativa. 2. ed. Porto Alegre: Bookman, 2006.

FREITAS, Tatiana Pereira. Autonomia e identidade profissional de professores de Educação Física diante da proposta curricular do Estado de São Paulo. 2011. $175 f$. Dissertação (Mestrado em Educação) - Faculdade de Educação, Pontifícia Universidade Católica, São Paulo, 2011.

GALATTI, Larissa; PAES, Roberto Rodrigues; DARIDO, Suraya Cristina. Pedagogia do esporte: livro didático aplicado aos Jogos Esportivos Coletivos. Motriz, Rio Claro, v. 16, n. 3, p. 534-555, jul./dez. 2010.

GASPARI, Telma Cristina et al. A realidade dos professores de Educação Física na escola: suas dificuldades e sugestões. Revista Mineira de Educação Física, Viçosa, v. 14, n. 1, p. 109-137, 2006.

LAVILLE, Christian; DIONNE, Jean. A construção do saber: manual de metodologia da pesquisa em ciências humanas. Porto Alegre: Artes Médicas, 1999.

MARCUSCHI, Luiz Antônio. Produção textual, análise de gêneros e compreensão. São 
MENDES, Edleise. Tipos e gêneros textuais: modos de leitura e de escrita. Signum, Londrina, v. 1, n. 11, p. 167-180, jul. 2008.

MORAES, Roque. Análise de conteúdo. Revista Educação, Porto Alegre, v. 22, n. 37, p. 7-32, 1999.

MOTTA, Carlos Eduardo de Souza. Indústria cultural e o sistema apostilado: a lógica do capitalismo. Cadernos Cedes, Campinas, v.21, n. 54, p. 82-89, ago. 2001.

MOTA JUNIOR, William Pessoa da; MAUÉS, Olgaíses Cabral. O Banco Mundial e as políticas educacionais brasileiras. Educação e Realidade, Porto Alegre, v. 39, n. 4, p. 1137-1152, out./ dez. 2014.

MUNAKATA, Kazumi. O livro didático como mercadoria. Pro-Posições, Campinas, v. 23, n. 3, p. 51-66, 2012.

NEVES, lara Conceição Bitencourt. (Org.). Ler e escrever: compromisso de todas as áreas. Porto Alegre: Editora da UFRGS, 1999.

PAULA, Maristela Vicente de. A utilização de apoio bibliográfico como recurso metodológico para o ensino da Educação Física nos níveis fundamental e médio de escolarização na cidade de Catalão-GO. 2003. 183 f. Dissertação (Mestrado em Educação Física) - Faculdade de Educação Física, Universidade de Campinas, Campinas, 2003.

RODRIGUES, Heitor de Andrade; DARIDO, Suraya Cristina. O livro didático na Educação Física escolar: a visão dos professores. Motriz, Rio Claro, v. 17, n. 1, p. 48-62, mar. 2011.

RUFINO, Luiz Gustavo Bonatto; DARIDO, Suraya Cristina. Educação Física Escolar, tema transversal saúde e livro didático: possíveis relações durante a prática pedagógica. Revista Brasileira de Ciência e Movimento, Brasília, v. 21, n. 3, p. 21-34, 2013.

SANTINI, Joarez; MOLINA NETO, Vicente. A síndrome do esgotamento profissional em professores de educação física: um estudo na rede municipal de ensino de Porto Alegre. Revista Brasileira de Educação Física e Esporte. São Paulo, v. 19, n. 3, p. 209-222, 2005.

SÃO PAULO. Secretaria Municipal de Educação. Diretoria de Orientação Técnica. Referencial de expectativas para o desenvolvimento da competência leitora e escritora no ciclo II do ensino fundamental. São Paulo: SME/DOT, 2006a.

SÃO PAULO. Secretaria Municipal de Educação. Diretoria de Orientação Técnica.

Referencial de expectativas para o desenvolvimento da competência leitora e escritora no ciclo Il: caderno de orientação didática de Educação Física. São Paulo: SME/DOT, 2006b.

SÃO PAULO. Secretaria Estadual de Educação. Currículo do Estado de São Paulo: Linguagens, códigos e suas tecnologias / Secretaria da Educação; coordenação geral, Maria Inês Fini; coordenação de área, Alice Vieira. - São Paulo: SEE, 2010.

SILVA, Ana Claudia et al. A leitura do texto didático e didatizado. In: BRANDÃO, Helena; MICHELETTI, Guaraciaba. (Coord.). Aprender e ensinar com textos didáticos e paradidáticos. 6. ed. São Paulo: Cortez, 2011. v. 2, p. 31-94.

SILVA, Marco Antônio. A fetichização do livro didático no Brasil. Educação e Realidade, Porto Alegre, v. 37, n. 3, p. 803-821, 2012. 
TRIVIÑOS, Augusto Nibaldo Silva. Introdução à pesquisa em ciências sociais. São Paulo, Atlas, 1987.

ZABALA, Antoni. A prática educativa: como ensinar. Porto Alegre: Artmed, 1998. 